\title{
ANÁLISIS JURÍDICO DE LOS ACUERDOS ENTRE TERCEROS Y COMUNIDADES NEGRAS PARA EL APROVECHAMIENTO FORESTAL EN EL DEPARTAMENTO DEL CHOCó*
}

\author{
Angie Katerine Palomeque Serna** \\ Lisneider Hinestroza Cuesta***
}

Fecha de recepción: 25 de enero de 2016

Fecha de evaluación: 18 de febrero de 2016

Fecha de aprobación: 10 de marzo de 2016

Artículo de investigación

DOI: http://dx.doi.org/10.18359/prole.1968

Forma de citación: Palomeque, A. \& Hinestroza, L. (2016). Análisis jurídico de los acuerdos entre terceros y comunidades negras para el aprovechamiento forestal en el departamento del Chocó. Revista Prolegómenos Derechos y Valores, 19, 38, 25-42. DOI: http://dx.doi.org/10.18359/prole.1968

\section{Resumen}

Este artículo tiene por objetivo analizar los acuerdos con terceros para el aprovechamiento forestal en territorios colectivos de comunidades negras. Utilizando la investigación documental, se revisó la legislación sobre aprovechamiento forestal expedida en Colombia comparándola con la legislación especial de comunidades negras para definir el alcance de los acuerdos entre los consejos comunitarios y terceros. Se concluye que los acuerdos con terceros son una actividad lícita, amparada por la ley 70/1993. Sin embargo, no hay lineamientos precisos salvo la persistencia del recurso forestal, que establezcan el alcance de este tipo de acuerdos y las normas por las que se rigen, si son las de derecho comercial, derecho civil o las de derecho propio.

\section{Palabras clave:}

Aprovechamiento forestal, comunidades negras, territorios colectivos, acuerdos con terceros.

\footnotetext{
Este artículo es resultado de la investigación adelantada por el Grupo de Investigación Derecho, Sociedad y Medio Ambiente (GIDSMA) que tiene como título: "Contratos de asociación con terceros para el aprovechamiento forestal en territorios de comunidades negras. Chocó. 2009-2013: análisis del alcance jurídico”. Proyecto financiado por el Departamento Administrativo de Ciencia, Tecnología e Innovación (Colciencias) y la gobernación del Chocó a través de FES, Programa Jóvenes Investigadores, modalidad tradicional. Convocatoria para la formación de capital humano de alto nivel para el departamento del Chocó. № 964.

** Abogada. Joven investigadora del Grupo de Investigación Derecho, Sociedad y Medio Ambiente en la Universidad Tecnológica del Chocó. Exbecaria Martin Luther King. Correo electrónico: angie.mosquera@utch.edu.co

**** Abogada, docente asistente de la Universidad Tecnológica del Chocó y líder del Grupo de Investigación Derecho, Sociedad y Medio Ambiente adscrito al Centro de Investigaciones en Biodiversidad y Hábitat de la misma universidad. Magíster en Derecho Programa Derecho de los Recursos Naturales de la Universidad Externado de Colombia (Bogotá, Colombia) y estudiante tercer año doctorado en Derecho de la Universidad Externado de Colombia. Correo electrónico: d-lisneider. hinestroza@utch.edu.co
} 


\title{
LEGAL ANALYSIS OF AGREEMENTS BETWEEN THIRD PARTIES AND BLACK COMMUNITIES FOR FORESTRY USE IN THE DEPARTMENT OF CHOCÓ
}

\begin{abstract}
Summary
This article aims to analyze agreements with third parties for forestry use in collective territories of black communities. Using documentary research, it was revised the legislation about forestry use issued in Colombia by comparing it with the special legislation of black communities to define the scope of the agreements between the community councils and third parties. It is concluded that agreements with third parties are a lawful activity, covered by the Act 70/1993. However, there are no precise guidelines, except for the persistence of the forest resource, laying down the scope of such agreements and the rules for which these are governed, if they are the ones of commercial law, civil law or own right.
\end{abstract}

\section{Keywords:}

Forestry use, black communities, collective territories, agreements with third parties.

\section{ANÁLISE JURÍDICA DOS ACORDOS ENTRE TERCEROS E COMUNIDADES NEGRAS PARA O APROVEITAMENTO FLORESTAL NO DEPARTAMENTO DE CHOCó}

\begin{abstract}
Resumo
Este artigo tem por objetivo analisar os acordos com terceiros para o aproveitamento florestal em territórios coletivos de comunidades negras. Utilizando a pesquisa documental foi revisada a legislação sobre aproveitamento florestal expedida na Colômbia comparando-a com a legislação especial de comunidades negras, para definir o alcance dos acordos entre os conselhos comunitários e terceiros. Conclui-se que os acordos com terceiros são uma atividade lícita, amparada pela Lei 70/1993. Porém, não há diretrizes precisas salvo a persistência do recurso florestal, que estabeleçam o alcance deste tipo de acordos e as normas pelas quais são regidos, se são as de direito comercial, direito civil ou as de direito próprio.
\end{abstract}

\section{Palavras-chave:}

Aproveitamento florestal, comunidades negras, territórios coletivos, acordos com terceiros.

\section{Introducción}

Históricamente en el país se han generado transformaciones significativas de los ecosistemas forestales naturales, por factores como la colonización, la realización de proyectos de infraestructura, el consumo de madera con fines energéticos, el establecimiento de cultivos ilícitos en áreas de vocación forestal, la explotación minera a cielo abierto y el uso de los bosques naturales de manera no sostenible, lo cual ha causado la desaparición y degradación de los bosques (Banco Internacional de Reconstrucción y Fomento, 2000). Así las cosas,

Los ecosistemas forestales, dados los beneficios ambientales, sociales, económicos y culturales que generan, tienen un gran reconocimiento a nivel internacional, generando la adopción de estrategias orientadas a su 
conservación, preservación, restauración y desarrollo sostenible, al interior de cada uno de los países (Banco Internacional de Reconstrucción y Fomento, 2000, p. 1).

Es evidente que los bosques como parte integrante y soporte de la diversidad biológica, étnica y de la oferta ambiental son un recurso estratégico de la nación y, por ende, su conocimiento y manejo son tarea esencial del Estado con apoyo de la sociedad civil (Ministerio del Medio Ambiente, 1996).

En Colombia el uso, manejo, aprovechamiento y conservación de los bosques y de la flora silvestre, tanto para la administración pública como para los particulares, los regula el decreto 1791/1996 (Hinestroza y Mena, 2011), que señala: "todo aprovechamiento forestal en Colombia se otorga mediante acto administrativo expedido por la Corporación Autónoma Regional y/o de Desarrollo Sostenible competente".

Ahora bien, el aprovechamiento forestal en el departamento del Chocó, se considera por tradición una de las actividades económicas de más arraigo para los grupos étnicos de la región, específicamente para las comunidades negras y resguardos indígenas, quienes según informes de la Corporación Autónoma Regional para el Desarrollo Sostenible del Chocó (Codechocó) son los principales titulares de los permisos y autorizaciones de aprovechamiento forestal (Hinestroza y Mena, s. f.).

Con la expedición de la ley 70/1993 o Ley de Negritudes, se pretendió no solo reconocer a las comunidades negras el derecho a la propiedad colectiva sobre los territorios que tradicionalmente habían ocupado, sino además, establecer mecanismos para la protección de la identidad cultural y de los derechos de estas comunidades como grupo étnico y el fomento de su desarrollo económico y social, con el fin de garantizar que las comunidades afrocolombianas, obtuvieran condiciones reales de igualdad de oportunidades frente al resto de la sociedad colombiana, como reza el artículo 1 de la precitada ley. Por su carácter de "Tierras de comunidades negras" estos territorios son inembargables, inalienables e imprescriptibles (Cossio, Agudelo, Hurtado, Mena e Hinestroza, s. f.).

Lo que se pretende con esta investigación es analizar los acuerdos con terceros para el aprovechamiento forestal en territorios colectivos de comunidades negras. El documento consta de una primera parte relacionada con el aprovechamiento forestal en la normatividad colombiana, concepto, clases y regulación normativa; una segunda sobre las comunidades negras y el aprovechamiento forestal; seguidamente se explicarán las funciones que cumplen los consejos comunitarios como máxima autoridad dentro de sus comunidades, como cuarto punto se explican los acuerdos con terceros para el aprovechamiento forestal en territorios colectivos de comunidades negras, luego se resuelve la pregunta: ¿son los acuerdos con terceros una modalidad de contratos atípicos? Y por último se dan las conclusiones.

\section{A. Metodología}

Para el desarrollo de la propuesta se utilizó la investigación documental expuesta por Toro y Parra (2010) quienes expresan que

[...] el desarrollo de toda propuesta de investigación, supone la revisión cuidadosa y sistemática de estudios, informes de investigación, literatura existente sobre el tema con el fin de contextualizarlo y lograr estar al día sobre lo que circula en el medio en relación con el tema que se pretende investigar (p. 412).

De acuerdo con lo anterior, se revisó la legislación expedida en Colombia sobre aprovechamiento forestal, comparándola con la legislación especial de comunidades negras para definir el alcance de los acuerdos con terceros para el aprovechamiento forestal en los territorios colectivos. Para el análisis de las normas que sirven de base a esta investigación, se parte de varios métodos de interpretación, entre ellos, el sistemático, sociológico y la crítica jurídica, acompañados de 
la interpretación de la norma en función del fin pragmático de la misma (Giraldo y Giraldo, 2002).

\section{B. Del aprovechamiento forestal en la normatividad colombiana}

Colombia pertenece a la "familia de la mega diversidad" junto con Brasil, Indonesia, Malasia, México, Zaire, Madagascar, Perú y Venezuela; más del $10 \%$ de las especies del planeta están representadas en Colombia y muchas de ellas son endémicas, es decir, exclusivas del país, pero la mayor parte de esa biodiversidad está en bosques y se sustenta de ellos (Hinestroza y Mena, 2011).

El aprovechamiento forestal ha tenido a lo largo de la historia una especial y profunda reglamentación en el ordenamiento jurídico, todo ello debido al importante enfoque que otorgó el constituyente de 1991 a la Constitución Política, que en palabras de la Corte Constitucional establece que:

[...] la protección del medio ambiente ocupa un lugar tan trascendental en el ordenamiento jurídico, que la Carta contiene una verdadera "Constitución ecológica" o "Constitución verde", conformada por todas aquellas disposiciones que regulan la relación de la sociedad con la naturaleza y que buscan proteger el medio ambiente (sentencia C-595/2010).

Dicho en otras palabras,

[...] la Constitución ecológica perfila un ideal social y político que busca transformaciones y ante todo la construcción de una verdadera "sociedad ecológica". La Constitución se transforma en un programa y el legislador no es un instrumento de acción política libre dentro de unos límites negativos que la Constitución impone, sino que él desarrolla el programa que la Constitución contiene (Amaya, 2006, p. 570).

El medioambiente entonces, se constituye no solo en elemento fundamental para la conservación de la vida en la tierra, sino en factor determinante para la salvaguarda de aspectos culturales y económicos de grupos poblacionales, es por ello la dualidad que adquiere, se convierte no solo en un derecho de todos los ciudadanos, sino también en un deber (Hinestroza y Mena, 2011), al respecto la Corte Constitucional manifiesta que: "El ambiente ha sido uno de los principales elementos de configuración y caracterización del orden constitucional instituido a partir de 1991" (sentencia C-123/2014).

En Colombia el uso, manejo, aprovechamiento y conservación de los bosques y de la flora silvestre, tanto para la administración pública como para los particulares, los regula el decreto 1791/1996, que señala: "todo aprovechamiento forestal en Colombia se otorga mediante acto administrativo expedido por la Corporación Autónoma Regional y/o de Desarrollo Sostenible competente".

Con la expedición del decreto ley 2811/1974 -Código Nacional de Recursos Naturales Renovables y de Protección al Medio Ambiente- se determinaron las áreas de reserva forestal (productoras, protectoras y productoras-protectoras) y se prohibió en estas la adjudicación de baldíos, salvo por razones de utilidad pública e interés social, siendo necesario delimitar y sustraer previamente las áreas respectivas. Igualmente se definieron los aprovechamientos forestales (persistentes, únicos y domésticos) que se adelantan en territorios de dominio público, previo el otorgamiento de permisos o a través de concesiones o asociaciones, y en los predios de propiedad privada deben contar con el aval de la autoridad ambiental (Hinestroza y Mena, 2011).

El decreto 1791/1996 en su artículo 1 define el aprovechamiento forestal como la extracción de productos de un bosque y comprende desde la obtención hasta el momento de su transformación. El artículo 5 del mismo decreto dicta varias clases de aprovechamiento forestal que dependen de la clase de propiedad sobre los bosques naturales en los que se autoriza la extracción de madera y su tipo de uso. 
Primero, aprovechamiento forestal único: se realiza una sola vez, en áreas donde con base en estudios técnicos se demuestre mejor aptitud de uso del suelo diferente al forestal o cuando existan razones de utilidad pública e interés social. Los aprovechamientos forestales únicos pueden contener la obligación de dejar limpio el terreno al término del aprovechamiento, pero no la de renovar o conservar el bosque.

Segundo, aprovechamiento forestal persistente: este es el que se efectúa con criterios de sostenibilidad y con la obligación de conservar el rendimiento normal del bosque con técnicas silvícolas, que permitan su renovación. Por rendimiento normal del bosque se entiende su desarrollo o producción sostenible, de manera tal que se garantice la permanencia del bosque.

Tercero, aprovechamiento forestal doméstico: se efectúa exclusivamente para satisfacer necesidades vitales domésticas sin que se puedan comercializar sus productos.

El artículo 55 del decreto 1791/1996 trae el aprovechamiento forestal de árboles aislados, el cual expresa que

[...] cuando se quiera aprovechar árboles aislados de bosque natural ubicados en terrenos de dominio público o en predios de propiedad privada que se encuentren caídos o muertos por causas naturales, o que por razones de orden sanitario debidamente comprobadas requieren ser talados, se solicitará permiso o autorización ante la corporación respectiva, que dará trámite prioritario a la solicitud.

De conformidad con lo dispuesto en el artículo 19 de la ley 70/1993 la utilización de recursos naturales renovables para construcción o reparación de vivienda, cercados, canoas y otros elementos domésticos para empleo de los integrantes de las comunidades negras de que trata dicha ley, se considera uso por ministerio de la ley, por lo que no requiere permiso ni autorización; dichos recursos, así como el resultado de la transfor- mación, no se podrían comercializar (art. 22, decreto 1791/1996).

Así pues, los aprovechamientos forestales de los árboles aislados y de usos por ministerio de la ley, no fueron incluidos en el decreto ley 2811/1974, sin embargo se pueden encontrar en el régimen forestal para Colombia, es decir, el decreto 1791/1996.

En la legislación forestal colombiana aparecen leyes y decretos (algunos vigentes y otros modificados) como: ley 93/1931, decreto 2278/1953, ley 2/1959, decreto 2811/1974, decreto 877/1976, decreto $622 / 1977$, decreto $1741 / 1978$, ley $37 / 1989$, ley $99 / 1993$, ley $139 / 1994$, decreto $1824 / 1994$, decreto 2915/1994, decreto 1791/1996, decreto $900 / 1997$ y decreto $1498 / 2008$. En el caso específico de las comunidades tenemos la ley 70/1993 o Ley de Comunidades Negras y el decreto 1745/1995.

La ley 70/1993 que en su artículo 19 consagra el aprovechamiento de uso por ministerio de ley, permite a estas comunidades que se asocien con terceros para realizar aprovechamiento forestal en sus territorios, cuando estas por razones económicas no puedan hacerlo (artículo 24).

Así pues, existe una nutrida legislación en materia de aprovechamiento forestal, no obstante, es muy poca la que se encuentra en relación con los bosques ubicados en territorios colectivos de comunidades negras.

\section{Las comunidades negras y el aprovechamiento forestal}

La ley 70/1993 como bien lo expresa el Instituto de Investigaciones Ambientales del Pacífico (citado en Rivas, Palomeque, Berardinelli e Hinestroza, 2016) es producto de la presión de dinámicas étnico-organizativas en el Pacífico colombiano, quienes alcanzaron a partir del ejercicio de promulgación de la Constitución Política de 1991, la conquista de algunos derechos como grupo étnico, en especial el derecho al territorio y 
su identidad étnica. La referida norma consagra en su artículo 1 lo siguiente:

La presente ley tiene por objeto reconocer a las comunidades negras que han venido ocupando tierras baldías en las zonas rurales ribereñas de los ríos de la Cuenca del Pacífico, de acuerdo con sus prácticas tradicionales de producción, el derecho a la propiedad colectiva, de conformidad con lo dispuesto en los artículos siguientes. Así mismo tiene como propósito establecer mecanismos para la protección de la identidad cultural y de los derechos de las comunidades negras de Colombia como grupo étnico y el fomento de su desarrollo económico y social, con el fin de garantizar que estas comunidades obtengan condiciones reales de igualdad de oportunidades frente al resto de la sociedad colombiana.

Es importante resaltar el significado de comunidad negra, siendo el conjunto de familias de ascendencia afrocolombiana que poseen una cultura propia, comparten una historia y tienen sus propias tradiciones y costumbres dentro de la relación campo-poblado, que revelan y conservan conciencia de identidad que las distinguen de otros grupos étnicos (Mena, s. f.).
El tipo de aprovechamiento forestal más utilizado en territorios colectivos de comunidades negras es el persistente, el cual se ejecuta con criterios de sostenibilidad y el de uso por ministerio de la ley. Así pues, son estas comunidades las únicas que pueden solicitar permisos de autorización para el aprovechamiento forestal a través de sus consejos comunitarios, tal como lo estipula el artículo 37 del decreto 1791/1996: "Las autorizaciones de aprovechamiento forestal de bosques naturales ubicados en terrenos de dominio privado, se otorgarán exclusivamente al propietario del predio", por ser estas comunidades las titulares de estos predios, quienes a su vez realizan el trámite mediante su junta directiva.

En el departamento del Chocó de acuerdo con información suministrada por la autoridad ambiental (Codechocó), entre los años 2009 y 2013 se otorgaron 197 autorizaciones de aprovechamiento forestal, a la fecha liquidadas formalmente en su totalidad y de las cuales 112 se concedieron a los consejos comunitarios de comunidades negras. Hay que destacar que, en la lista de municipios que más han recibido dichas autorizaciones, se encuentran: Riosucio, Quibdó, Río Quito, Cantón de San Pablo, Istmina, Novita y El Carmen del Darién.

Tabla 1. Autorizaciones de aprovechamiento forestal otorgadas en el departamento del Chocó 2009-2013

\begin{tabular}{lcccc}
\hline \multicolumn{1}{r}{ Municipio } & Consejo comunitario & Resguardo indígena & Persona natural & Total \\
\hline Acandí & 2 & 0 & 1 & 3 \\
Atrato & 0 & 0 & 1 & 1 \\
Bajo Baudó & 2 & 0 & 0 & 2 \\
Cantón de San Pablo & 5 & 0 & 4 & 9 \\
Carmen de Atrato & 0 & 0 & 2 & 2 \\
Cértegui & 1 & 5 & 0 & 6 \\
Istmina & 10 & 0 & 1 & 11 \\
Juradó & 1 & 1 & 0 & 2 \\
Lloró & 1 & 4 & 3 & 8 \\
Medio Atrato & 1 & 0 & 0 & 1
\end{tabular}




\begin{tabular}{lcccc}
\hline \multicolumn{1}{r}{ Municipio } & Consejo comunitario & Resguardo indígena & Persona natural & Total \\
\hline Novita & 2 & 0 & 0 & 2 \\
Quibdó & 11 & 3 & 7 & 21 \\
Tadó & 1 & 0 & 7 & 8 \\
Unguía & 0 & 0 & 4 & 4 \\
Alto Baudó & 1 & 2 & 0 & 3 \\
Bagadó & 0 & 0 & 4 & 4 \\
Bahía Solano & 0 & 0 & 3 & 3 \\
Bojayá & 0 & 8 & 0 & 8 \\
El Carmen del Darién & 15 & 1 & 0 & 16 \\
Litoral de San Juan & 3 & 0 & 0 & 3 \\
Medio Baudó & 1 & 1 & 0 & 2 \\
Nuquí & 0 & 0 & 7 & 7 \\
Río Quito & 7 & 1 & & 8 \\
Riosucio & 48 & 3 & 4 & 56 \\
Medio y Bajo Baudó & 1 & 1 & 0 & 1 \\
Unión Panamericana & 12 & 0 & 0 & 1 \\
Istmina y Medio San Juan & 1 & 0 & 0 & 1 \\
Riosucio-Belén & 1 & 0 & 3 & 4 \\
Total & & 30 & 54 & 197 \\
\hline
\end{tabular}

Fuente: elaboración propia con base en datos suministrados por Codechocó mediante radicado 2015-3-1327 de 14 de julio de 2015.

Tabla 2. Autorizaciones de aprovechamiento forestal otorgadas a consejos comunitarios de comunidades negras

\begin{tabular}{llc}
\hline \multicolumn{1}{c}{ Municipio } & \multicolumn{1}{c}{ Consejo comunitario } & Total \\
\hline Cantón de San Pablo & Mayor del Cantón de San Pablo Acinsap & 2 \\
\multirow{2}{*}{ Istmina } & Mayor de Istmina y parte del & 5 \\
& Medio San Juan Cocominsa & 2 \\
Novita & Mayor de Novita & 2 \\
Quibdó & De Novita & 2 \\
& Asociación Campesina del Atrato Cocomacia & 3 \\
El Carmen del Darién & De la Madre & 3 \\
& De Domingodó & 2 \\
Río Quito & De Montaño & 2 \\
& De Villa Conto & 3 \\
& San Isidro & 2
\end{tabular}




\begin{tabular}{llc}
\hline Municipio & \multicolumn{1}{c}{ Consejo comunitario } & Total \\
\hline & Dos Bocas & 2 \\
& Pegadita-Macilla & 3 \\
& Bocas de Taparal & 2 \\
& Mayor de Quiparadó & 2 \\
& Domingodó & 2 \\
Cuenca de Cacarica & 6 \\
Riosucio & Truandó Medio & 3 \\
& Mayor de la Cuenca del Río Salaquí & 5 \\
& Del Río Salaquí & 3 \\
& Clavellino & 2 \\
& Quiparadó & 2 \\
& La Larga Tumaradó & 2 \\
\hline
\end{tabular}

Fuente: elaboración propia con base en datos suministrados por Codechocó mediante radicado 2015-3-1327 de 14 julio de 2015.

\section{Los consejos comunitarios: autoridades de administración interna de comunidades negras}

El desarrollo jurídico del artículo transitorio 55 de la Constitución Política dio como fruto la ley 70/1993 y el decreto 1745/1995, el cual crea los consejos comunitarios como entes responsables de la administración de los territorios colectivos titulados a las comunidades negras (Proyecto protección de tierras y patrimonio de la población desplazada, 2010), los reconoce como las máximas autoridades administrativas dentro del colectivo ancestral y son ellos a quien el Instituto Colombiano de Desarrollo Rural (Incoder) le entrega el título colectivo adjudicado como "Tierra de comunidades negras".

Entre los beneficios que ha permitido la ley mencionada está la creación de consejos comunitarios de comunidades negras (Mena citado en Rivas et al., 2016), que se presenta como una oportunidad para que los grupos de comunidades locales se organicen y se integren en el proceso étnico organizativo por el territorio. Son entidades étnicas territoriales, responsables de administrar el territorio dentro del cual tienen jurisdicción, organización que trabaja por la defensa de los derechos colectivos de sus comunidades locales. Durante la década de los noventa y en el marco de la ley 70/1993, muchas poblaciones afrodescendientes conquistaron espacios de participación, con el objetivo de conseguir las reivindicaciones étnico-territoriales que se luchaban: titulación colectiva de los territorios que habitaban sobre la cuenca del Pacífico, protección a la identidad étnica y cultural y reconocimiento de la organización comunitaria, entre otras (Rodríguez, 2004). Así las cosas, la titulación colectiva en el Pacífico se viene adjudicando a través de solicitudes que hacen los distintos consejos comunitarios (asambleas generales de miembros que integran las comunidades negras) (Rivas et al., 2016).

De conformidad con información suministrada por el Incoder (regional Chocó), en Colombia entre 1996 y 2012 se otorgaron 181 títulos colectivos a comunidades negras, representadas por los consejos comunitarios, siendo el Chocó el departamento con más títulos colectivos, con un $57 \%$ respecto a los demás departamentos, es decir, se han concedido 60 títulos colectivos (véase tabla 3). 
Tabla 3. Títulos colectivos otorgados en el departamento del Chocó

\begin{tabular}{|c|c|c|c|}
\hline No. & Municipio & Consejo comunitario & Resolución \\
\hline 1 & Alto Baudó & Bellavista Dubasa & 1219 de 1 de junio de 2000 \\
\hline 2 & Bajo Baudó & Piliza & 3367 de 21 de diciembre de 2001 \\
\hline 3 & Bajo Baudó & Pizarro & 1122 de 16 de mayo de 2001 \\
\hline 4 & Bajo Baudó & San Agustín de Terrón & 03369 de 21 de diciembre de 2000 \\
\hline 5 & Riosucio (El Carmen del Darién) & Chicao & 0285 de 13 de diciembre de 1996 \\
\hline 6 & Acandí & Río Acandí Zona Costera Norte & 1501 de 1 de agosto de 2005 \\
\hline 7 & $\begin{array}{l}\text { Alto, Medio, Bajo Baudó, Río Quito } \\
\text { y Cantón de San Pablo }\end{array}$ & Río Baudó y sus afluentes - Acaba & 1152 de 23 de mayo de 2001 \\
\hline 8 & El Carmen del Darién & Turriquitado & 2799 de 22 de noviembre de 2000 \\
\hline 9 & Bajo Baudó y Litoral del San Juan & Concosta & 1123 de 16 de mayo de 2001 \\
\hline 10 & Bajo Baudó & Virudó & 2698 de 21 de diciembre de 2000 \\
\hline 11 & Alto Baudó & Puerto Echeverri & 1218 de 1 de junio de 2000 \\
\hline 12 & Quibdó & Casimiro & 2429 de 1 de diciembre de 2005 \\
\hline 13 & Acandí & Río Acandí Seco, El Cedro y Juancho & 1499 de 1 de agosto de 2005 \\
\hline 14 & Tadó & Mayor del Alto San Juan - Asocasan & 2727 de 27 de diciembre de 2001 \\
\hline 15 & Quibdó & Guayabal & 0051 de 1 de julio de 2003 \\
\hline 16 & Riosucio (El Carmen del Darién) & Apartadó - Buena Vista & 0159 de 9 de febrero de 1998 \\
\hline 17 & Riosucio & Cacarica & 0841 de 26 de abril de 1999 \\
\hline 18 & Alto Baudó & San Francisco de Cugucho & 0156 de 9 de febrero de 1998 \\
\hline 19 & Riosucio & Río Salaquí & 02802 de 22 de noviembre de 2000 \\
\hline 20 & Bajo Baudó & Cuevita & 2701 de 21 de diciembre de 2001 \\
\hline 21 & Medio Baudó & Río Pepe & 1125 de 23 de mayo de 2000 \\
\hline 22 & Riosucio & La Nueva & 0289 de 13 de diciembre de 1996 \\
\hline 23 & Bajo Baudó & Pavasa & 2695 de 21 de diciembre de 2001 \\
\hline 24 & Novita & Novita & 2693 de 21 de diciembre de 2001 \\
\hline 25 & Río Quito & San Isidro & 0157 de 9 febrero de 1998 \\
\hline 26 & Juradó & Juradó & 02199 de 3 de diciembre de 2002 \\
\hline 27 & Nuquí & Los Riscales & 2206 de 4 de diciembre de 2002 \\
\hline 28 & Bahía Solano & Cupica & 2700 de 21 de diciembre de 2000 \\
\hline 29 & Bajo Baudó & San Andrés de Usaragá & 3368 de 21 de diciembre de 2000 \\
\hline 30 & Cértegui & Cértegui & 2728 de 27 de diciembre de 2000 \\
\hline 31 & Acandí & Río Tolo Zona Costera Sur & 1502 de 1 de agosto de 2005 \\
\hline
\end{tabular}




\begin{tabular}{|c|c|c|c|}
\hline No. & Municipio & Consejo comunitario & Resolución \\
\hline 32 & Riosucio & Dos Bocas & 0288 de 13 de diciembre de 1996 \\
\hline 33 & El Carmen del Darién & La Grande & 2806 de 22 de noviembre de 2000 \\
\hline 34 & Riosucio & La Madre & 0286 de 13 de diciembre de 1996 \\
\hline 35 & Istmina y Medio San Juan & Istmina y Medio San Juan & 1176 de 16 de julio de 2002 \\
\hline 36 & Cantón de San Pablo & Acisanp & 2694 de 21 de diciembre de 2001 \\
\hline 37 & Condoto & Condoto & 1177 de 16 de julio de 2002 \\
\hline 38 & Riosucio & Clavellino & 0290 de 13 de diciembre de 1996 \\
\hline 39 & Río Quito & Villa Conto & 0160 de 9 de febrero de 1998 \\
\hline 40 & $\begin{array}{l}\text { Quibdó, Atrato, Río Quito, Medio } \\
\text { Atrato, Bojayá, Vigía del Fuerte, } \\
\text { Murindó y Urrao de Antioquia }\end{array}$ & Asociación Integral del Atrato - Acia & 4566 de 29 de diciembre de 1997 \\
\hline 41 & Riosucio & Pedeguita y Mancilla & 2804 de 22 de noviembre de 2000 \\
\hline 42 & Bajo Baudó & Villa María de Purricha & 1129 de 23 de mayo de 2000 \\
\hline 43 & Bajo Baudó & Siviru & 1144 de 14 de mayo de 2007 \\
\hline 44 & El Carmen del Darién & Río Jiguamiandó & 2801 de 22 de noviembre de 2000 \\
\hline 45 & El Carmen del Darién & Río Curvaradó & 2809 de 22 de noviembre de 2000 \\
\hline 46 & Riosucio & Truandó Medio & 3366 de 21 de diciembre de 2000 \\
\hline 47 & El Carmen del Darién & Montaño & 2807 de 22 de noviembre de 2000 \\
\hline 48 & Riosucio & Bocas de Taparal & 2803 de 13 de noviembre de 2000 \\
\hline 49 & El Carmen del Darién & Río Domingodó & 2803 de 22 de noviembre de 2000 \\
\hline 50 & Riosucio & La Larga Tumaradó & 2805 de 22 de noviembre de 2000 \\
\hline 51 & El Carmen del Darién & $\begin{array}{l}\text { Vigía de Curvaradó y Santa Rosa de } \\
\text { Limón }\end{array}$ & 2808 de 22 de noviembre de 2000 \\
\hline 52 & Unguía & Bajo Atrato & 0048 de 21 de julio de 2003 \\
\hline 53 & Río Quito & Paimadó & 2726 de 27 de diciembre de 2001 \\
\hline 54 & $\begin{array}{l}\text { Litoral del San Juan, Istmina y } \\
\text { Novita }\end{array}$ & Acadesan & 2702 de 21 de diciembre de 2001 \\
\hline 55 & Bahía Solano y Juradó & Los Delfines & 002200 de 3 de diciembre de 2002 \\
\hline 56 & Unión Panamericana & Cocomaupa & 2723 de 27 de diciembre de 2001 \\
\hline 57 & Atrato, Lloró, Bagadó, Cértegui & Cocomapoca & 02425 de 19 de septiembre de 2011 \\
\hline 58 & Riosucio & Río Quiparadó & 2798 de 22 de noviembre de 2000 \\
\hline 59 & Lloró & Consejo Comunitario Integ. de Lloró & 2919 de 21 de diciembre de 2012 \\
\hline 60 & Atrato & Consejo Comunitario de la Molana & 00631 de 10 de marzo de 2015 \\
\hline
\end{tabular}

Fuente: elaboración propia con base en datos suministrados por Incoder mediante radicado 00195 de 19 de mayo de 2015. 
En cuanto a las atribuciones que la ley le ha otorgado a los consejos comunitarios, en la tabla 4 se ilustran algunas normas sobre asignaciones espe- cíficas para el tema de aprovechamiento forestal en territorios colectivos de comunidades negras.

Tabla 4. Normativa sobre consejos comunitarios y aprovechamiento del recurso forestal

\begin{tabular}{|c|c|}
\hline Constitución Política de 1991 & $\begin{array}{l}\text { Artículo transitorio 55. "Dentro de los dos años siguientes a la entrada en vigencia } \\
\text { de la presente Constitución, el Congreso expedirá, previo estudio por parte de } \\
\text { una comisión especial que el Gobierno creará para tal efecto, una ley que les re- } \\
\text { conozca a las comunidades negras que han venido ocupando tierras baldías en las } \\
\text { zonas rurales ribereñas de los ríos de la Cuenca del Pacífico, de acuerdo con sus } \\
\text { prácticas tradicionales de producción, el derecho a la propiedad colectiva sobre las } \\
\text { áreas que habrá de demarcar la misma ley. En la comisión especial de que trata } \\
\text { el inciso anterior tendrán participación en cada caso representantes elegidos por } \\
\text { las comunidades involucradas. La propiedad así reconocida solo será enajenable } \\
\text { en los términos que señale la ley. La misma ley establecerá mecanismos para la } \\
\text { protección de la identidad cultural y los derechos de estas comunidades, y para el } \\
\text { fomento de su desarrollo económico y social". }\end{array}$ \\
\hline $\begin{array}{l}\text { Ley } 70 / 1993, \text { "por la cual se desa- } \\
\text { rrolló el artículo transitorio } 55 \text { de la } \\
\text { Constitución Política" }\end{array}$ & $\begin{array}{l}\text { Artículo 19. "Las prácticas tradicionales que se ejerzan sobre las aguas, las playas } \\
\text { o riberas, los frutos secundarios del bosque o sobre la fauna y flora terrestre y } \\
\text { acuática para fines alimenticios o la utilización de recursos naturales renovables } \\
\text { para construcción o reparación de viviendas, cercados, canoas y otros elemen- } \\
\text { tos domésticos para uso de los integrantes de la respectiva comunidad negra se } \\
\text { consideran usos por ministerio de la ley y en consecuencia no requieren permiso. } \\
\text { Estos usos deberán ejercerse de tal manera que se garantice la persistencia de } \\
\text { los recursos, tanto en cantidad como en calidad. El ejercicio de la caza, pesca o } \\
\text { recolección de productos para la subsistencia, tendrá prelación sobre cualquier } \\
\text { aprovechamiento comercial, semiindustrial, industrial o deportivo". } \\
\text { Artículo 24. "La entidad administradora de los recursos naturales renovables regla- } \\
\text { mentará concertadamente con las comunidades negras el uso colectivo de áreas del } \\
\text { bosque a que se refiere la presente ley, para el aprovechamiento forestal persistente. } \\
\text { Para efectos del aprovechamiento, el procesamiento o la comercialización de los } \\
\text { productos forestales que se obtengan en desarrollo de la concesión forestal, la comu- } \\
\text { nidad concesionaria podrá entrar en asociación con entidades públicas o privadas". }\end{array}$ \\
\hline $\begin{array}{l}\text { Decreto } 1745 / 1995, \text { "por el cual se } \\
\text { reglamenta el capítulo III de la Ley } 70 \\
\text { de } 1993 \text {, se adopta el procedimiento } \\
\text { para el reconocimiento del derecho a } \\
\text { la propiedad colectiva de las 'Tierras } \\
\text { de las comunidades negras' y se dic- } \\
\text { tan otras disposiciones" }\end{array}$ & $\begin{array}{l}\text { Artículo 10. Principios. "El presente decreto se fundamenta en los principios y } \\
\text { derechos de que trata la Constitución Política y las leyes } 70 \text { de } 1993 \text { y } 21 \text { de } 1991 \text {, } \\
\text { y dará aplicación a los principios de eficacia, economía y celeridad, con el objeto } \\
\text { de lograr la oportuna efectividad de los derechos reconocidos en dichas normas". } \\
\text { Artículo 12. Funciones del representante legal del consejo comunitario. "[...] Nu- } \\
\text { meral 3. Presentar, ante la autoridad ambiental competente y ante el Ministerio de } \\
\text { Minas y Energía, las solicitudes de aprovechamiento, exploración y explotación de } \\
\text { recursos naturales, en beneficio de la comunidad, previa aprobación de la Junta } \\
\text { del Consejo Comunitario; exceptuándose, los usos por ministerio de la ley, respec- } \\
\text { to de los recursos naturales renovables". }\end{array}$ \\
\hline $\begin{array}{l}\text { Decreto } 1791 / 1996, \text { "por medio del } \\
\text { cual se establece el régimen de apro- } \\
\text { vechamiento forestal" }\end{array}$ & $\begin{array}{l}\text { Artículo 22. "De conformidad con lo dispuesto en el artículo } 19 \text { de la ley } 70 \text { de } \\
1993 \text { (5), la utilización de recursos naturales renovables para construcción o repa- } \\
\text { ración de viviendas, cercados, canoas y otros elementos domésticos para uso de } \\
\text { los integrantes de las comunidades negras de que trata dicha ley se consideran usos } \\
\text { por ministerio de la ley, por lo que no requieren permiso ni autorización; dichos } \\
\text { recursos, así como el resultado de su transformación, no se podrán comercializar". }\end{array}$ \\
\hline
\end{tabular}




\begin{tabular}{|l|l|}
\hline $\begin{array}{l}\text { Ley 99/1993, "por medio de la cual } \\
\text { se establece el régimen de aprove- } \\
\text { chamiento forestal" }\end{array}$ & $\begin{array}{l}\text { Artículo 76. De las comunidades indígenas y negras. "La explotación de los recur- } \\
\text { sos naturales deberá hacerse sin desmedro de la integridad cultural, social y econó- } \\
\text { mica de las comunidades indígenas y de las negras tradicionales de acuerdo con la } \\
\text { ley } 70 \text { de } 1993 \text { y el artículo } 330 \text { de la Constitución Nacional y las decisiones sobre } \\
\text { la materia se tomarán, previa consulta a los representantes de tales comunidades". }\end{array}$ \\
\hline $\begin{array}{l}\text { Decreto 1320/1998, "por medio del } \\
\text { cual se reglamenta la consulta previa } \\
\text { con las comunidades indígenas y ne- } \\
\text { gras para la explotación de los recur-- } \\
\text { sos naturales dentro de su territorio" }\end{array}$ & $\begin{array}{l}\text { Capítulo IV. Consulta previa en materia de permisos de uso, aprovechamiento o } \\
\text { afectación de recursos naturales renovables. "Se podrá realizar consulta previa para } \\
\text { obtener permiso de aprovechamiento forestal en aquellos territorios de dominio } \\
\text { público, que a pesar de no haber sido adjudicados por el Incoder y se consideren } \\
\text { baldíos a cargo del Estado colombiano son habitados por afrodescendientes". }\end{array}$ \\
\hline
\end{tabular}

Fuente: elaboración propia con base en la revisión documental de normatividad.

Lo anterior significa que las comunidades negras, a través de la junta directiva del consejo comunitario, deberán establecer mecanismos de administración y manejo que garanticen la equidad y justicia en el reconocimiento y asignación de áreas de trabajo para las familias, que eviten la concentración de las tierras en pocas manos y que permitan un aprovechamiento sostenible de los recursos naturales del cual se beneficien todos los integrantes de la comunidad, en cumplimiento de la función social y ecológica de la propiedad (art. 32, ley 70/1993).

Sin embargo, aun cuando los consejos comunitarios estén estructurados en formas tradicionales de organización social, el nuevo reto lo constituye la función de Gobierno y de planificación del territorio que le exige su papel como autoridad étnica. Toda vez que, pese al reconocimiento de los derechos territoriales de las comunidades étnicas y al desarrollo de sus particulares formas organizativas, desde hace casi dos décadas, tanto pueblos indígenas como comunidades negras se han visto altamente afectadas por el desplazamiento forzado y por el aprovechamiento indiscriminado de los recursos naturales, en una clara disputa por sus territorios (Proyecto protección de tierras y patrimonio de la población desplazada, 2010).

\section{E. Acuerdos con terceros en el aprovechamiento forestal en territorios colectivos de comunidades negras}

En este acápite se hablará de los contratos o acuerdos realizados entre los consejos comuni- tarios y terceros para el aprovechamiento forestal en territorios colectivos de comunidades negras, de conformidad con lo establecido en el artículo 24 de la ley 70/1993.

Para las comunidades negras, la expresión "territorios colectivos" no solo refleja su forma de apropiación territorial, es también el reconocimiento a la manera de usar las tierras que ocupaban, es una visión filosófica y práctica de relacionarse y de vivir, donde el territorio está integrado por más elementos que establece la ley 70/1993, que circunscribe la definición de "territorio colectivo" a la noción de "tierras de comunidades negras", así el artículo 4 de ley en cita dispone que "los terrenos respecto de los cuales se determine el derecho a la propiedad colectiva se denominarán para todos los efectos legales tierras de comunidades negras".

El contrato a favor de terceros constituye una figura autónoma que se viene formando a través de un lento proceso, para responder a necesidades de la práctica que no serán satisfechas, o lo serían mal, acudiendo a otros institutos con los que se guarda algún parentesco (López, 1971). Tal y como lo expresa López:

Según nuestro código, dadas ciertas condiciones se puede contratar eficazmente en nombre de otro (representación directa), $y$ en nombre propio, pero a favor de otro (contrato a favor de tercero). He aquí dos instituciones que han nacido -por así decirlo- en rebeldía a un viejo axioma romano: 
alteri stipulare nemo potest (1971, p. 323).

Por su parte, la Enciclopedia Jurídica (2014) expresa que el contrato a favor de tercero, conocido también como estipulación a favor de tercero, es una figura jurídica en la que hay un contratante, llamado promitente, que se compromete frente a otro, denominado promisario, a realizar una determinada prestación a favor de un tercero, llamado beneficiario. Cuando este acepta el beneficio previsto a su favor, consolida su situación contractual. El beneficiario puede ser persona determinada al perfeccionarse el contrato entre promitente y promisario; pero puede ser designada más tarde por el promisario y nunca por el promitente. La aceptación del beneficiario debe comunicarse al promitente. La base más normal de este contrato es que alguien acredite de su deudor lo mismo que debe a su acreedor.

En relación con las comunidades negras, la ley 70/1993 les otorgó a estas comunidades organizadas en consejos comunitarios, la facultad de entrar en asociación con entidades públicas o privadas, sin embargo, no existen desarrollos normativos que claramente establezcan el alcance de este tipo de contratos o asociaciones. En este orden ideas, la disposición citada en materia de contrato de asociaciones reza lo siguiente:

Artículo 24. La entidad administradora de los recursos naturales renovables reglamentará concertadamente con las comunidades negras el uso colectivo de áreas del bosque a que se refiere la presente ley, para el aprovechamiento forestal persistente. Para efectos del aprovechamiento, el procesamiento o la comercialización de los productos forestales que se obtengan en desarrollo de la concesión forestal, la comunidad concesionaria podrá entrar en asociación con entidades públicas o privadas.

Se puede evidenciar, que en materia de contratos no existen desarrollos normativos que fijen el alcance de esta clase de contratos o asociaciones, las normas que se aplican, si son las de derecho civil, derecho comercial o las normas de derecho propio. De igual forma, la ley 70/1993 no contempla en específico cómo deben estructurarse este tipo de contratos establecidos en su artículo 24; por lo anterior ha sido necesario remitirse a doctrina de algunos autores en la materia, aunque en sus explicaciones no se detallan los contratos que en concreto celebren grupos étnicos, sino que se hace referencia a acuerdos o contratos en general.

El contrato puede definirse como un acuerdo de voluntad encaminado a satisfacer la necesidad que tienen las personas, naturales o jurídicas, públicas o privadas de obtener bienes o servicios, mediante convenciones regladas, bien sea por la ley o las partes y de las que se derivan derechos y obligaciones. Así, los contratos nacen como usos sociales, simples hábitos, que evolucionan a costumbres jurídicas, caracterizadas estas últimas por su coercibilidad, hasta que, por intervención del legislador, se tornan en contratos típicos (Garcés, 2014). Así mismo, Rodríguez (s. f.) sostiene que

Si el contrato o concurso de voluntades tiene por objeto crear obligaciones, recibe el nombre de contrato. Podemos definirlo con la convención generadora de obligaciones o bien el acuerdo de las voluntades de dos o más personas destinado a crear obligaciones (p. 3).

A modo de comparación entre las normas de derecho comercial, civil y laboral, Wilches (2014, p. 92) expresa

Para iniciar, mencionemos que el Código Civil colombiano define contrato o convención como el "[...] acto por el cual una parte se obliga para con otra a dar, hacer o no hacer alguna cosa" (República de Colombia, 1887, artículo 1495) mientras que el Código de Comercio colombiano define al contrato como "[...] un acuerdo de dos o más partes para constituir, regular o extinguir entre ellas una relación jurídica patrimonial".

En el Código de Comercio se indica que en 
[...] los contratos mercantiles de ejecución periódica o sucesiva, cada una de las partes, podrá hacerse sustituir, por un tercero, en la totalidad o en parte de las relaciones derivadas del contrato sin necesidad de aceptación expresa del contratante cedido. Si por la ley o por estipulación de las mismas partes no se ha prohibido o limitado dicha sustitución (Superintendencia Bancaria, 1999).

Para algunos tratadistas entre contrato civil y comercial no existe una fundamental diferencia, así lo afirma el maestro Cervante Ahumada (citado en Mestre, 2013, p. 33): "Según indicamos al hablar de la unificación del derecho civil y el derecho mercantil en materia de obligaciones y contratos, no existe diferencia alguna fundamental en la estructura orgánica de unos y otros contratos". En otras palabras,

[...] el derecho mercantil o comercial es una rama o materia nueva en relación con el derecho civil, en un principio no se preocupaba por regular los aspectos jurídicos entre los comerciantes, en la actualidad este derecho también se preocupa por regular las relaciones jurídicas de aquellos que no son comerciantes pero que efectúan actos $u$ operaciones de comercio (Ortiz, 2010, p. 6).

Por su parte, la definición de contrato de trabajo hecha por Rodríguez (2012) expresa que es a través de este que una persona natural se obliga a prestar un servicio personal a otra persona natural o jurídica, bajo la continuada dependencia o subordinación de esta y mediante una remuneración.

Como se observa, se trata de un convenio jurídico y donde se establece la reciprocidad de prestar un servicio de carácter personal a cambio de una remuneración. Dicho contrato se somete al ordenamiento imperativo de orden público, que no permite libertades y por el contrario controla la autonomía de las partes (Rodríguez, 2012).

Lo anterior deja entrever las apreciaciones de los diferentes autores respecto de los contratos, que en este texto siguiendo a Uribe (1976, pp. 2-20), se han clasificado así:

Contratos unilaterales es decir, cuando ha de producir obligaciones "primarias" a cargo de una sola parte y bilaterales si está destinado a que las partes contraigan recíprocamente obligaciones de esta naturaleza; contratos gratuitos o de beneficencia cuando solo tiene por objeto la utilidad de una de las partes, sufriendo la otra el gravamen y onerosos cuando tiene por objeto la utilidad de ambos contratantes, gravándose cada uno a beneficio del otro; contratos conmutativos, es decir, cuando cada una de las partes se obliga a dar o hacer una cosa que se mira como equivalente a lo que la otra parte debe dar o hacer a su vez y si el equivalente consiste en una contingencia incierta de ganancia o pérdida, se llama aleatorio; contrato principal, es cuando subsiste por sí mismo sin necesidad de otra convención y accesorio, cuando tiene por objeto asegurar el cumplimiento de una obligación principal, de manera que no pueda subsistir sin ella; contrato real es cuando, para que sea perfecto, es necesaria la tradición de la cosa a que se refiere. Solemne, cuando está sujeto a la observancia de ciertas formalidades especiales, de manera que sin ellas no produce ningún efecto civil y consensual, cuando se perfecciona por el solo consentimiento; de ejecución instantánea, cuando de los objetos de las obligaciones que generan se ejecutan en un solo acto único, sin dilación y de ejecución sucesiva, cuando tales objetos no pueden ejecutarse al punto, sino en varios acto escalonados.

También encontramos los contratos atípicos (innominados), que son los que no tienen una disciplina jurídica propia y contratos típicos (nominados), que son los que tienen mención y sobre todo regulación básica en la ley o en una norma de carácter obligatorio. Generalmente la regulación es supletiva en el sentido de que ella contendrá tan solo las reglas a las que deben sujetarse los particulares que no han introducido por medio de sus propias cláusulas modificaciones a la re- 
glamentación legal (Mestre, 2013). Así las cosas, existe una amplia clasificación de los contratos comerciales; sin embargo deberemos resolver el siguiente interrogante: ¿son los acuerdos con terceros una modalidad de contratos atípicos? En virtud del principio de la libertad contractual, los individuos pueden, al disponer de sus intereses, recurrir a los tipos contractuales fijados previamente por el ordenamiento o utilizar figuras negociables no reconocidas en forma expresa por la ley, pero sí por la sociedad, siempre y cuando no contraríen normas de orden público o las buenas costumbres (Mantilla y Ternera, 2009), pero en el caso de las comunidades negras no son intereses de una persona en particular sino los intereses de todos los que están en juego.

Dentro de las diversas definiciones de contratos atípicos se observa que con frecuencia los doctrinantes recurren a aquella según la cual: "los contratos atípicos o innominados son los que no tienen una disciplina jurídica propia". Esto significa que los contratos atípicos (o innominados) son los que no tienen una regulación legal específica; no están tipificados y, en consecuencia, son atípicos (Mestre, 2013). Por su parte, el tratadista Francesco Messineo (s. f.) expresa:

Se llaman también atípicos, precisamente porque se separan de las figuras de los contratos nominativos, que están dotados de una causa típica que caracteriza la respectiva disciplina; en los contratos innominados, la causa precisamente atípica, porque es nueva y diversa, respecto de una de las que son propias de los contratos nominados.

Vale la pena decir, que

[...] el comportamiento de las partes en un contrato atípico es una directriz fundamental que sirve para desentrañar la voluntad negocial, de tal manera que no es una exageración afirmar que de dicho comportamiento dependen la mayoría de las veces los efectos finales que el juzgador le reconoce a los actos de disposición innominados que celebran los particulares y que son objeto de discusión en sede judicial o arbitral (Mantilla y Ternera, 2009).

Así pues, si seguimos las reglas de la legislación civil y comercial, los contratos de asociación o acuerdos con terceros se clasificarían dentro de los contratos atípicos o innominados, toda vez que este tipo de contratos son los que no tienen una regulación legal específica; no están tipificados y, por tanto, son atípicos (Mestre, 2013), y si bien los contratos de acuerdos con terceros están contemplados en el artículo 24 de la ley 70/1993, no existe una estructura de cómo deben desarrollarse los mismos, ni las normas o principios por las que deben regirse, al menos de la formalidad jurídica. Pero la pregunta de análisis sería si estamos en presencia de otro tipo de acuerdos considerando que estamos ante una modalidad no tradicional de poseer y ser propietario de territorios y no de cosas, como se trata de la propiedad colectiva de las comunidades negras.

\section{Conclusiones}

Los acuerdos entre terceros y las comunidades negras son una actividad lícita, amparada por la ley 70/1993, no obstante no hay lineamientos precisos salvo la persistencia del recurso forestal, que establezcan el alcance de esta clase de acuerdos y las normas por las que se rigen, es decir, si son las de derecho comercial, derecho civil o las de derecho propio.

Los contratos de asociación o acuerdos con terceros son una modalidad de los contratos atípicos o innominados, toda vez que este tipo de contratos son los que no tienen una regulación legal específica; no están tipificados, y por ello, son atípicos.

Teniendo en cuenta que las comunidades negras tienen el derecho de propiedad del territorio, de los suelos y los bosques, los actos de disposición facultan para la celebración de este tipo de acuerdo que debería regirse por las normas propias o acuerdos de cada consejo comunitario en consideración de sus prácticas culturales, 
productivas y las restricciones establecidas por la legislación especial de comunidades negras como la garantía de la persistencia del recurso forestal.

Si bien en Colombia existe una nutrida legislación en materia de aprovechamiento forestal, es muy poca la que se refiere a territorios colectivos de comunidades negras.

El decreto 1791/1996 en su artículo 22 y la ley 70/1993 en su artículo 19 han dejado a discreción de las comunidades negras la clase de aprovechamiento de usos por ministerio de ley, toda vez que las comunidades se escudan en este tipo de aprovechamiento para evadir los controles de la policía a la hora de sacar el recurso forestal de los territorios.

Existe una afectación de los territorios colectivos de comunidades negras, por el uso irracional de los recursos forestales, de lo que deriva además, la afectación del medioambiente como derecho colectivo. Con el uso irracional $e$ ilegal del recurso forestal, se perjudica a estas comunidades entorno a sus prácticas tradicionales de producción, tanto física como cultural.

Existe inasistencia, falta de capacitación y de implementación de programas por parte de las autoridades competentes en materia de aprovechamiento forestal hacia las comunidades negras, tendientes al mejoramiento y fortalecimiento de la explotación de los recursos forestales de una manera sustentable, por ello estas comunidades a través de sus consejos comunitarios, como máxima autoridad administrativa dentro de los territorios colectivos, se ven en la obligación de elaborar contratos de asociación con terceros, por cuanto en la mayoría de los casos, no cuentan con los recursos económicos ni con la maquinaria para contratar profesionales del área, que les elaboren un plan de manejo forestal.

\section{Referencias}

Amaya, O. (2006). Algunos de los principales desarrollos normativos de la Constitución
Política de 1991 en materia ambiental. Bogotá: Universidad Externado de Colombia.

Banco Internacional de Reconstrucción y Fomento. (2000). Plan nacional de desarrollo forestal. Bogotá: BIRF.

Constitución Política de Colombia. (1991). Artículo 55

Corte Constitucional de Colombia. (2010). Sentencia C-595. M. P: Jorge Iván Palacio Palacio.

Corte Constitucional de Colombia. (2014). Sentencia C-123. M. P.: Alberto Rojas Ríos.

Cossio, F. C., Agudelo, M. F., Hurtado, J. H. A., Mena, M. \& Hinestroza, L. (s. f.). El rol de los consejos comunitarios de las comunidades negras en la adjudicación de permisos de aprovechamiento forestal en el departamento del Chocó. Artículo inédito. Chocó.

Decreto 2278 de 1953. Por el cual se dictan medidas sobre cuestiones forestales. Septiembre 21. DO. 28294

Decreto ley 2811 de 1974. Por el cual se dicta el Código Nacional de Recursos Naturales Renovables y de Protección al Medio Ambiente. Diciembre 18. DO. 34243.

Decreto 622 de 1977. Por el cual se reglamentan parcialmente el capítulo V, título II, parte XIII, libro II del decreto-ley número 2811 de 1974 sobre "sistema de parques nacionales"; la ley 23 de 1973 y la ley 2 de 1959. Marzo 16

Decreto 1741 de 1978. Por el cual se reglamentan parcialmente la ley 23 de 1973, el decretoley 2811 de 1974 y los decretos 2349 de 1971 y 133 de 1976, en lo relacionado con la creación de un área de manejo especial. Agosto 4. DO. 35088.

Decreto 1824 de 1994. Por el cual se reglamenta parcialmente la ley 139 de 1994 . Agosto 3. DO. 41473.

Decreto 2915 de 1994. Por el cual se organiza la Unidad Administrativa Especial del Sistema de Parques Nacionales Naturales, 
se asignan funciones y se dictan otras disposiciones. Diciembre 31. DO. 41663.

Decreto 1791 de 1996. Por medio del cual se establece el régimen de aprovechamiento forestal. Octubre 4.

Decreto 900 de 1997. Por el cual se reglamenta el Certificado de Incentivo Forestal para Conservación. Abril 1. DO. 43013.

Decreto 1320 de 1998. Por el cual se reglamenta la consulta previa con las comunidades indígenas y negras para la explotación de los recursos naturales dentro de su territorio. Julio 15. DO. 43340.

Decreto 1498 de 2008. Por el cual se reglamenta el parágrafo $3^{\circ}$ del artículo $5^{\circ}$ de la ley 99 de 1993 y el artículo $2^{\circ}$ de la ley 139 de 1994. Mayo 7. DO. 46982.

Enciclopedia Jurídica. (2014). Contrato a favor de tercero. Disponible en: http://www. enciclopedia-juridica.biz14.com/d/contrato-en-favor-de-tercero/contrato-en-favorde-tercero.htm

Garcés, J. (2014). Contratación atípica en el sector central de la administración pública colombiana (ministerios y departamentos administrativos). Memoria presentada como requisito para optar al título de magíster en Derecho Administrativo. Universidad Colegio Mayor de Nuestra Señora del Rosario. Facultad de Jurisprudencia. Maestría en Derecho Administrativo.Bogotá.

Giraldo, J. \& Giraldo, O. (2002). Metodología y técnica de la investigación jurídica. Bogotá: ABC.

Hinestroza, L. \& Mena, M. (s. f.). Estudio jurídico sobre el otorgamiento de permisos de aprovechamiento forestal en territorios colectivos de comunidades negras en el Chocó 2004-2011. Artículo inédito. Quibdó.

Hinestroza, L. \& Mena, M. (s. f.) El aprovechamiento forestal en el Chocó 2009-2013: sanciones administrativas y responsabilidad penal. Artículo inédito. Quibdó.
Hinestroza, L. \& Mena, M. (2011). Análisis sobre el marco jurídico que regula el aprovechamiento forestal en Colombia. Revista Biodiversidad Neotropical, 1(2), pp. 73-90.

Ley 57 de 1887. Por medio de la cual se expide el Código Civil colombiano. Mayo 26.

Ley 31 de 1931. Por la cual se fomenta la explotación de productos forestales. Marzo 31. DO. 21633.

Ley 2 de 1959. Por la cual se dictan normas sobre economía forestal de la nación y conservación de recursos naturales renovables. Diciembre 16.

Ley 37 de 1989. Por la cual se dan las bases para estructurar el Plan Nacional de Desarrollo Forestal y se crea el Servicio Forestal. Abril 3. DO. 38761.

Ley 70 de 1993. Por la cual se desarrolló el artículo transitorio 55 de la Constitución Política. Agosto 27.

Ley 99 de 1993. Por la cual se crea el Ministerio del Medio Ambiente, se reordena el sector público encargado de la gestión y conservación del medio ambiente y los recursos naturales renovables, se organiza el Sistema Nacional Ambiental, Sina, y se dictan otras disposiciones. Diciembre 22. DO. 41146.

Ley 139 de 1994. Por la cual se crea el Certificado de Incentivo Forestal y se dictan otras disposiciones. Junio 21. DO. 41401.

Ley 1333 de 2009. Por medio de la cual se crea el régimen sancionatorio ambiental. Julio 21. DO. 47417.

Ley 1450 de 2011. Por la cual se expide el Plan Nacional de Desarrollo. Junio 16. DO. 48102.

López, F. (1971). Teoría de los contratos. Parte general. Buenos Aires: Alberdi 385.

Mantilla, F. \& Ternera, F. (2009). Los contratos en el derecho privado. Bogotá: Legis Editores S. A. 
Mena, A. M. (s. f.). Identificación y análisis de indicadores sociales en la minería artesanal en los territorios colectivos de las comunidades negras de Condoto y Tadó en el área de influencia del Programa Oro Verde. Quibdó.

Messineo, F. (s. f.). Manual de derecho civil y comercial: derecho de las obligaciones parte general. Tomo IV. Buenos Aires: Ediciones Jurídicas Europa-América.

Mestre, A. (2013). Naturaleza jurídica del contrato de outsourcing. Trabajo de grado para optar al título de abogada. Corporación Universidad Rafael Núñez. Facultad de Ciencias Sociales y Humanas. Centro de Investigaciones Cartagena de Indias.

Ministerio de Medio Ambiente. (1996). Política de bosques, documento Conpes 2834. Bogotá: Minambiente.

Ortiz, E. (2010). El contrato de concesión comercial como un modo de comercialización de bienes y servicios. Trabajo de grado para optar al título de abogada. La Cuenca, Ecuador.

Proyecto Protección de Tierras y Patrimonio de la Población Desplazada. (2010). Los consejos comunitarios y la protección de los territorios colectivos. Bogotá.

Rodríguez, A. (s. f). De los contratos. Santiago de Chile: Temo S. A.
Rodríguez, J. (2012). Guía relaciones laborales y prestaciones. Colombia.

Rodríguez, S. (2004). Movimiento étnico afrocolombiano en el quehacer político de Tumaco. Análisis Político, 52, pp. 90-102. Colombia.

Superintendencia Bancaria. (1999). Concepto 1999016252-2. Disponible en: http://legal. legis.com.co/Search/Search

Rivas, J. Palomeque, A. Berardinelli, N. \& Hinestroza, L. (2016). Afectación del derecho al medio ambiente sano en la comunidad de Condoto-Chocó por el otorgamiento de títulos mineros a empresas multinacionales. Revista Pensamiento Jurídico. Universidad Nacional de Colombia. Colombia.

Toro, I. D. \& Parra, R. D. (2010). Fundamentos epistemológicos de la investigación y la metodología de la investigación "cualitativa y cuantitativa" ( $1^{a}$ ed.). Medellín: Fondo Editorial Eafit.

Uribe, R. (1976). Teoría de los contratos. Bogotá: Ediciones Rosario.

Wilches, R. (2014). La protección del ambiente en el contrato a la luz de las teorías del derecho de contratos. Estudio a partir del derecho comercial colombiano. Revista Opinión Jurídica, 130(25), pp. 87-104. 